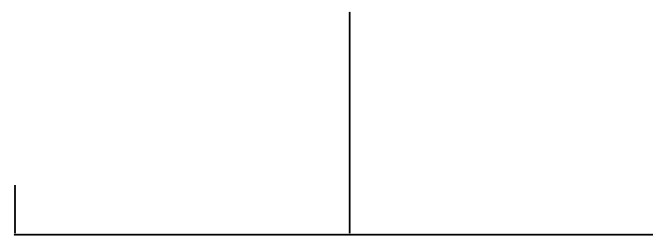

Rev. Latinoam. Psicopat. Fund., São Paulo, v. 15, n. 1, p. 94-107, março 2012

\title{
A dimensão da ética nas intervenções do analista frente às demandas institucionais dos CAPS
}

\author{
Volnei Antonio Dassoler \\ Claudia Maria de Sousa Palma
}

Diante da complexidade que envolve a construção da clínica no campo psicossocial, cabe ao analista interrogar sobre a sua contribuição na qualificação dessa proposta. A questão se apresenta como um particular desafio, decorrente dos questionamentos sobre os limites da prática psicanalítica, considerando a diferença com o padrão clínico convencional e a presença dos atravessamentos institucionais e políticos. Nessa perspectiva, indicamos a noção de ética como conceito diferenciado e norteador da clínica psicanalítica na sua contribuição aos tratamentos ofertados nos CAPS.

Palavras-chave: Clínica psicanalítica, clínica psicossocial, ética, saúde mental

* A reflexão que este artigo propõe é parte integrante da dissertação de mestrado do Programa de Pós-Graduação em Psicologia concluída na Universidade Federal de Santa Maria no ano de 2010: "As intervenções do analista frente às demandas institucionais dos CAPS". A pesquisa foi composta a partir de entrevistas com oito analistas, integrantes de equipes de CAPS do Rio Grande do Sul e do Rio de Janeiro, buscando identificar como e de que forma estes analistas estabeleciam as escoras simbólicas para a clínica que desenvolviam nestes serviços, desde o campo da psicanálise. 


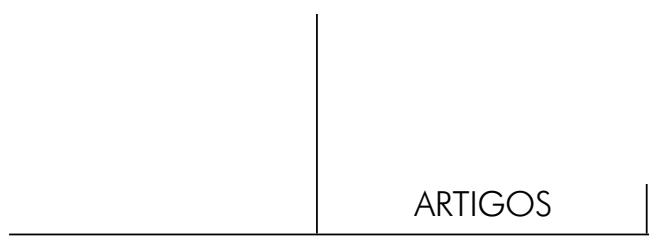

\section{Introdução}

A terapêutica psicossocial formulada nos serviços oriundos da Reforma Psiquiátrica ganhou contornos políticos e clínicos decorrentes do processo de transformação da atenção à saúde mental, em especial, aquela executada no âmbito público e que tem, nos Centros de Atenção Psicossocial (CAPS), seu maior representante. Da parte da psicanálise, entendemos que a mesma colabora quando se torna propositiva ao indicar uma operatividade clínica para este contexto, sem, com isso, exigir o apagamento das diretrizes orientadoras da clínica no campo da saúde mental em articulação com a especificidade do tratamento analítico, isto é, o singular das vicissitudes de um sujeito na busca da satisfação pulsional.

Para o propósito de nosso estudo, é conveniente definir que a população que acessa a rede de atendimento psicossocial caracteriza-se pela precariedade de seu vínculo com o Outro, ${ }^{1}$ tipificada nas psicoses, nos transtornos graves de desenvolvimento na infância e na recorrente ruptura dos vínculos sociais em pacientes com uso abusivo de álcool e outras drogas.

Historicamente, a trajetória teórica e clínica da psicanálise revela que estes quadros clínicos não recebiam a anuência de Freud para o tratamento psicanalítico, deixando clara sua restrição quanto à aplica-

1. Outro: lugar onde a psicanálise situa, para além do parceiro imaginário, aquilo que, anterior e exterior ao sujeito, não obstante o determina. Chemama, 1995, p. 156. 
bilidade do processo analítico às configurações não neuróticas, conforme registra no texto "Sobre a psicoterapia" (1907). Entretanto, ele sugere uma viabilidade futura do procedimento, desde que novos estudos e desenvolvimentos clínicos sejam realizados:

Psicoses, estados de confusão e depressão profundamente arraigados (poderia dizer tóxicos) não se prestam, portanto, a psicanálise, pelo menos não para o método que vem sendo praticado até o presente. Não considero de modo algum impossível que, mediante modificações adequadas do método, possamos ser bem-sucedidos em superar essa contraindicação - e assim podermos iniciar uma psicoterapia das psicoses. (p. 274)

Nessa direção, no texto "Linhas de progresso na terapia psicanalítica" (1919), encontramos Freud projetando a inserção da técnica psicanalítica como recurso terapêutico junto à população em geral por meio de médicos preparados que, com outros profissionais e de forma gratuita, prestariam atendimento em centros clínicos para pacientes externos de camadas sociais mais amplas, acometidos por graves sofrimentos psíquicos. Cito Freud:

Defrontar-nos-emos, então, com a tarefa de adaptar nossa técnica às novas condições [...]. No entanto, qualquer que seja a forma como essa psicoterapia para o povo possa assumir, quaisquer que sejam os elementos dos quais se componha, os seus ingredientes mais efetivos e importantes continuarão a ser, certamente, aqueles tomados a psicanálise estrita e não tendenciosa. (p. 181)

A posição esclarecida de Freud ratifica que esta exigência é endereçada a cada analista que se propor ao exercício da psicanálise no espaço privado e nas diferentes configurações que poderia incluir a proposta analítica. Depreende-se, pois, que não se trata de criar novos conceitos para garantir o selo analítico, mas de um apelo ao esforço de situar a especificidade do fazer analítico, posição compartilhada por Quinet (2009) quando lembra que o particular da psicanálise não está no formalismo prático, e sim no rigor de uma ética que é particular ao ofício do analista. Diante disso, o analista compromete-se com os desdobramentos clínicos específicos de seu trabalho, a partir de determinadas categorias conceituais, sem se confundir com a submissão a procedimentos protocolares distantes da clínica psicanalítica.

Para Monteiro e Queiroz (2006), a ampliação do método freudiano, para além do lócus original, pode se efetivar quando toma como premissa a ideia de que "como método de tratamento e investigação, a psicanálise se insere em uma ética fundada a partir da solução singular dada pelo sujeito à errância do seu desejo e a seu modo de gozo" (p. 112), fato que pode ocorrer em diferentes contextos e independentemente da modalidade do dispositivo clínico-institucional, seja este individual, coletivo, regular ou mesmo numa situação única. Segundo as autoras, 


\section{SAÚDE MENTAL}

o analista avança e garante a presença da dimensão analítica ao "sustentar o lugar social do sujeito a partir de sua diferença, e não pelo universal dos direitos do cidadão. Isto pode ser feito através da posição de escuta do analista sobre o que há de específico em cada sujeito" (p. 113). Este registro ratifica o entendimento de que a contribuição da psicanálise nestes espaços passa por realçar as vias de acesso à subjetividade em seus diferentes lugares de produção, deixando evidente que a aposta não se encontra nos formatos das modalidades de atendimento, o que significaria a técnica reduzida a si mesma.

Em um de seus textos, onde discute as questões sobre a técnica, Freud (1912) pondera que as regras com as quais pauta seu trabalho resultam apropriadas à sua individualidade, considerando ser possível que, em outras pessoas ou em outras circunstâncias, estas possam se expressar de maneira diferente. Nesse sentido, propõe em "Sobre o início do tratamento" (1913) que as mesmas sejam tomadas como recomendações, comparando o tratamento analítico a um jogo de xadrez e sua infinita variedade de jogadas, afirmando "a extraordinária diversidade de constelações psíquicas envolvidas, a plasticidade de todos os processos mentais e a riqueza dos fatores determinantes oporem-se a qualquer mecanização da técnica" (p. 164). Ao fazer tal comparação, Freud sugere que as regras seriam pormenores cuja importância se estabelece no "plano geral do jogo", por estarem subordinadas ao que acontece durante o mesmo. Consideramos, no entanto, que não se trata de controlar ou antecipar o efeito do que se configura como imprevisível na experiência analítica, mas de manter a relação entre o dispositivo clínico e o discurso analítico sob invariáveis que qualificam a prática em questão como analítica, quando cotejada às outras modalidades de tratamento.

\section{A realidade psíquica e a questão da ética}

Partindo do sofrimento histérico, a reflexão freudiana problematiza os termos vigentes no terreno da ciência e da moral, campos que, prioritariamente, definiam os padrões de normalidade e de psicopatologia. Sua elaboração interroga o grau de responsabilidade subjetiva envolvida no sofrimento mental, e define uma posição ética para o praticante de psicanálise que lhe demarca um estilo de clínica peculiar.

De maneira precisa, o ensinamento de Freud avança na direção de sinalizar a inexistência de uma ordenação pacífica entre o eu e o isso e o mundo externo, e a implicação do sujeito sobre o destino da sua neurose. No artigo "Notas adicionais sobre a interpretação de sonhos como um todo" (1925), Freud aborda a questão da responsabilidade do sujeito diante do conteúdo da produção oní- 
rica, sugerindo que este material, uma vez interpretado, revela a presença de desejos imorais de difícil aceitação consciente pelo sujeito por estarem relacionados à realização incestuosa, sádica e masoquista. Sem abrir mão de suas convicções, ressignifica a relutância do sonhador e dá indicações do embasamento ético que funda a escuta analítica e da qual um analista não deve se afastar, independentemente do lócus da clínica:

Obviamente, temos que nos considerar responsáveis pelos impulsos maus de nossos sonhos. Que mais se pode fazer com eles? A menos que o conteúdo dos sonhos (corretamente entendido) seja inspirado por espíritos estranhos, ele faz parte do seu próprio ser. Se procuro classificar os impulsos presentes, em mim, segundo padrões sociais, em bons e maus, tenho de assumir responsabilidade por ambos os tipos; e, se em defesa digo que o desconhecido, inconsciente e recalcado em mim não é meu "eu", não estarei baseando na psicanálise minha posição. (p. 165)

Podemos perceber acima, um indicativo para o que pode vir a ser designada como a ética do analista, enquanto uma posição relativa a sustentar o lugar da emergência do sujeito do inconsciente para o sujeito, mesmo diante da recusa deste por não se reconhecer nas hiâncias do discurso, na brevidade dos lapsos e no gozo do sintoma pela descarga da pulsão de morte. Nesse sentido, o tratamento proposto por Freud elege o recurso simbólico da fala em associação livre como meio de tratamento ao psíquico, buscando atribuir significação ao que emerge como desconhecido e acidental, ou seja, aquilo que faz furo na pretensa totalidade do eu.

No clássico, A interpretação dos sonhos (1900), Freud deixa claro que o inconsciente testemunha a divisão psíquica do sujeito, e que a realidade psíquica pode ser designada como uma apropriação singular decorrente da própria condição de acesso e de estruturação dos processos inconscientes, manifestando-se sempre de forma parcial:

Se olharmos para os desejos inconscientes reduzidos à sua mais fundamental e verdadeira forma, teremos de concluir, fora de dúvida, que a realidade psíquica é uma forma especial de existência que não deve ser confundida com a realidade material... (p. 658)

Essa leitura do inconsciente é ratificada por Figueiredo e Machado (2000) ao avançar nas intervenções dos analistas e sua forma particular de diagnóstico:

A realidade psíquica, portanto, não se reduz ao ego-realidade, embora o inclua, do mesmo modo que inclui o sintoma. Sua fonte primária é o inconsciente, em sua dimensão desconhecida, que emerge através da fala a que temos acesso e à qual, de algum modo, respondemos. É na própria palavra do sujeito que começa o trabalho clínico. Ao tratarmos do sofrimento psíquico só podemos fazê-

Rev. Latinoam. Psicopat. Fund., São Paulo, v. 15, n. 1, p. 94-107, março 2012 


\section{SAÚDE MENTAL}

-lo pelo que aparece dessa realidade em palavras e ações prenhes de sentido. Trata-se da única realidade que diz respeito e interessa ao sujeito, a partir da qual ele se vê, pensa, fala, sofre, trabalha, enfim, se põe no mundo e até mesmo se desconhece. (p. 66-67)

Dessa maneira, interessa-nos situar a realidade psíquica como um fato de linguagem, designação que lhe atribui pertinência clínica, ao reconhecer efetividade para aquilo que ocorre entre paciente e analista nos diferentes contextos deste encontro.

\section{A ética discursiva}

Lacan destina um de seus seminários anuais para discutir as questões que envolvem a noção de ética no campo da psicanálise. Como de costume, ele trilha os textos freudianos para pautar o debate, em especial aqueles nos quais Freud se ocupa em contestar a ideia de que a felicidade existe como um destino para a humanidade. Para sustentar o alcance dessa ideia na clínica, Lacan retoma um termo freudiano das Ding (a Coisa), estabelecido no "Projeto para uma psicologia científica" (1895). Neste estudo, considerado uma transição de Freud do campo neurológico para a cena psicológica, a noção de "Coisa" é estabelecida para representar a ideia da existência de algo fora da linguagem e que nunca teria adquirido materialidade. Assim, Lacan (1959), no seminário sobre a ética, vai descrever a "Coisa" como sendo aquilo que "não pode ser reencontrado ... objeto perdido ... em torno do que se orienta todo o encaminhamento do sujeito" (p. 69) e "anterior a todo recalque" (p. 71).

Dessa forma, por ser anterior à incidência do eixo simbólico na subjetividade, não se encontraria subordinada aos juízos relativos às montagens de satisfação, mediadas pela linguagem, mostrando-se como um gozo desprovido de sentido. Precisamente, nesse caso, das Ding comparece para designar a origem do desejo enquanto resultado de uma perda radical e permanente do seu primeiro objeto de satisfação. Privado deste desfecho, o sujeito é confrontado com a insaciabilidade do seu desejo, sendo lançado ao mundo em busca de uma felicidade que não se alcança, uma vez que não há, conforme argumenta Freud (1930), algo materializável que corresponda ao que foi perdido. Quer dizer, há algo anterior ao simbólico que resiste à cadeia significante, por evidenciar-se como falta estrutural. Nas palavras de Lacan (1959), “... é que ela é, essa Coisa, o que do real primordial, diremos, padece do significante" (p. 149) por constituir-se anterior a todo recalque, na medida em que o significante do Nome-do-Pai, ao fazer seu comparecimento, deixa isso fora. 
Com efeito, mesmo estando fora da cadeia significante, a Coisa, designação para o real, requer tratamento, ou seja, lhe cabe as mãos do oleiro, conforme metáfora de Lacan no Seminário 7 - A ética da psicanálise. A via de tratamento para isso que surge como desmedido é a circunscrição, ou seja, o contorno, feito a partir de uma tessitura entre os significantes disponíveis no campo semântico do sujeito. Com efeito, o suporte simbólico é uma via fundamental de tratamento para o gozo do real, recurso da terapêutica proposto por Freud na medida em que fazer falar, a partir da transferência, permite circunscrever o real e fazer borda ao irrepresentável. A partir de agora, a verdade deve ser localizada, por escansão, no encontro com o indizível.

Diante desse fato de estrutura, resta ao sujeito, como nos fez saber Freud, o recurso simbólico de tratar o inominável, ou seja, de encontrar palavras para responder, até onde alcança, sobre o vazio que impera na existência. Dessa forma, o caráter de irrecuperabilidade do objeto original lança o humano à vida, circunstância determinante da existência que irá pautar a escuta do analista como avessa a qualquer forma de normalização do desejo e, portanto, da conduta humana. Tendo isso em consideração e lembrando as particularidades evidenciadas na clínica psicossocial, a ética do analista passa a ser uma bússola que orienta as intervenções nesse cenário, na sustentação do desejo, como sendo aquilo que, do sujeito, aponta para o singular e para os modos como situa seu gozo no laço social. Uma ética voltada à sustentação do desejo não significa, conforme nos diz Kehl (2002), levá-lo às últimas consequências do individualismo moderno que postula a sua realização a qualquer custo.

O desejo, diz a autora, não é propriedade privada do sujeito, senão que é próprio da condição humana, sem advogar para o sujeito o lugar da exceção. Essa é a banalidade revelada pela psicanálise, afirmando que "a dimensão da singularidade está, antes, nas soluções de compromisso encontradas no sintoma do que propriamente no desejo" (p. 132). Dentro dessa lógica, o trabalho clínico desenvolvido no ambiente psicossocial afasta-se da regulação moralizadora dos códigos de conduta, favorecendo o protagonismo do sujeito e o caráter de solução do sintoma como uma forma de afirmação singular e de existência no laço social.

\section{A posição ética do analista frente às demandas institucionais dos CAPS}

O analista, desde seu lugar clínico, legitima a falta como possibilidade de haver o exercício do desejo, postura que se contrapõe à demanda de completude e cura que pode advir dos pacientes, usuários e técnicos dos CAPS. No seminário sobre a ética, Lacan (1959) diz convicto: “... o que nos demandam, é 


\section{SAÚDE MENTAL}

preciso chamá-lo por uma palavra simples, é a felicidade" (p. 350). O que faz, então, um analista em resposta a esse pedido? Retomando o tema pela releitura de Freud, o autor argumenta que se não há felicidade a ser alcançada, nem objeto a ser reencontrado, não pode haver, por parte do analista, nenhuma conduta afirmativa sobre o acesso à felicidade (p. 350).

$\mathrm{O}$ autor recoloca a questão de outra forma, quando menciona que não há possibilidade de responder à demanda de felicidade pela razão óbvia de que propor-se a isso equivaleria a pressupor a existência de um Bem Supremo que concederia esse estado de plenitude. Todavia, do ponto de vista da psicanálise, esse objeto não existe, aliás, ele só se materializa, na perspectiva imaginária, como ilusão dessa aquisição. Esse, afinal, é o status dos bens oferecidos pela propaganda e por inúmeras teorias psicológicas. Precavendo-se dessa armadilha, Lacan (1959) aponta a inacessibilidade a esse objeto, porque "o analista não o tem, como sabe que não existe" (p. 359).

Dessa forma, a ética pensada por Lacan é a ética relativa ao desejo, na qual o desejo se apresenta como motor da existência e promotor da possibilidade de vida. Assim, não se trata de promover o bem-estar, entendido como resultado da obtenção dos bens acessíveis, mas de ofertar um bendizer que fique bem ao sujeito à medida que possibilita alguma satisfação e circulação no laço social. Portanto, a ética diz respeito a uma interrogação que vincula uma relação entre a ação e o desejo que a sustenta.

Seria possível pensar a existência do pedido de felicidade (completude) no âmbito psicossocial, visto que, nesse cenário, há uma precariedade que alcança os níveis mais fundamentais da existência material e psíquica? Podemos, sim, assinalar que existem expectativas vinculadas ao tratamento, mas estas estão associadas à aquisição ou ao restabelecimento de um determinado padrão de conduta social, isto é, não há, nesta versão, um pedido de felicidade ou de plenitude endereçado aos CAPS ou aos analistas.

Precisamente, o pedido almeja o retorno a uma condição de normalidade correspondente a um estado de controle psíquico, o qual permitiria um manejo efetivo sobre o desregramento nas condutas dos alcoolistas, toxicômanos, autistas e psicóticos. Quer dizer, a demanda de felicidade, localizada na clínica privada, parece encontrar correspondência na noção de cura e adaptação, inscritas no campo psicossocial. Mesmo que o ideal esteja situado numa outra ordem de carência, acreditamos que essa diferença não muda, estruturalmente, aquilo que se pede ao analista e aos demais componentes da equipe, ou seja, o impossível. Só que, nesses casos, o impossível da relação sexual, conforme axioma de Lacan, é vertido na garantia da abstinência no uso de substâncias psicoativas, na aquisição de uma racionalidade neurótica para os psicóticos e numa infância sem transtornos em seu desenvolvimento, demandas que são insistentemente endereçadas pelos familiares e pelas instituições sociais. 
Considerando a manutenção do cuidado e a necessidade de resposta à singularidade, o trabalho do analista é aquele que tenta trazer à cena institucional o que dela fica excluído, isto é, suporta a emergência dos restos singulares daquilo que escapa à pretensão universalizante dos projetos políticos no campo da saúde. Assim, a introdução de dispositivos clínicos, quando fundados na lógica psicanalítica, funcionam como ancoragem para o acolhimento das condutas percebidas como estranhas, intratáveis e inesperadas que, sob a ótica analítica, são percebidas como indicadores do arranjo psíquico de cada sujeito. Ou seja, vincular a ética com a questão do discurso permite pensarmos na possibilidade de vincular as manifestações dos pacientes como significantes que podem adquirir estatuto psíquico pelo trabalho do analista. Dessa forma, tanto as consultas individuais como as demais atividades realizadas nos CAPS - como as reuniões de equipe, matriciamento, supervisão, interconsultas, intervenções de urgência, oficinas, dentre outras - convertem-se em possibilidades para a presença do discurso analítico.

Assim, entendemos que, frente às demandas institucionais dos CAPS, é viável ao analista, tanto a participação nos dispositivos já existentes como a proposição de novos recursos clínicos, visto que a sua prática diferencia-se daquelas dos demais integrantes da equipe, pela particular posição quanto à escuta do sujeito do inconsciente. Esta especificidade não está dada, portanto, do lado do formato ou do enquadre das atividades, e sim nas condições de enunciação e da posição ética do analista frente a ela, indicando, com isso, que o psicanalista, ao se situar com relação à demanda, o faz pela via de sustentação de uma questão e não por uma resposta encaminhada como solução para aquilo que lhe foi endereçado.

\section{Conclusão}

As instituições como os CAPS, frutos da reforma psiquiátrica, não criam apenas um novo espaço terapêutico para o sujeito nomeado, pela política, como usuário. Criam, também, um novo lugar para o analista, endossando a produção de novas práticas, em especial aquelas que apostam no coletivo como um recurso terapêutico que favorece o restabelecimento do suporte social dos pacientes. Com efeito, o analista não visa saber o que fazer para resolver a precariedade do sujeito, mas, tomando o enunciado como referência, visa a dimensão da enunciação, que pode ser acionada com uma convocação: "o que isso quer dizer para você?" e "o que isso faz para a sua existência". Figueiredo (2010) vai nessa direção e propõe que, em vez do trabalho ser desencadeado pela pergunta, o que 


\section{SAÚDE MENTAL}

podemos fazer por ele, a intervenção do analista e da própria equipe deve mirar outra direção: "o que ele pode fazer, através da nossa oferta, para sair de sua condição como algo imutável e poder seguir adiante em um novo movimento?", sinalizando que no tratamento concebido a partir da psicanálise, o sujeito é chamado a indagar sobre si, sobre sua vida e os outros que o cercam, movimento que requer esforço em se debruçar sobre as contingências da sua vida.

Nessa direção, localizamos duas diferenças que consideramos fundamentais para demarcar a especificidade da psicanálise no trato com a falta, sendo determinantes na clínica promovida nos CAPS. A primeira diz respeito ao fato de o saber acerca do sintoma ser construído com o sujeito, ou seja, ele não é oferecido exteriormente àquele que padece, ou seja, o sintoma não é um entrave a ser retirado, mas indica um modo possível de como o sujeito fez sua vida. Trata-se, portanto, de colocá-lo favoravelmente nessa direção. A segunda está relacionada à concepção da noção de falta. Para a psicanálise, a falta está estruturalmente posta como condição de subjetivação, tradução do acesso necessário à existência. Com isso, o que se propõe ao sujeito em tratamento não diz respeito a completar ou eliminar a falta, mas de produzir algo a partir dela. Assim, a nuance ética que se coloca para o analista, desde o início, é a escolha sobre os modos de resposta às demandas que lhe são dirigidas $\mathrm{e}$, da parte do sujeito, o aparelhamento, via sintoma, a partir de uma posição de responsabilidade acerca das suas formas de gozo.

Nessa nova proposta, o sintoma alcança o estatuto de solução psíquica, de recurso estabilizador da existência, privilegiando uma abordagem diferente às patologias psíquicas graves, onde o analista, do seu lugar, visa promover algum tipo de aproximação do sujeito com o Outro, via sintoma; relação cavada pela introdução de suportes simbólicos que possam engajá-lo no laço social. Assim, o trabalho do analista pressupõe tomar o tratamento ao gozo como recurso que permite a construção de algum vínculo com o laço social, tomando o ambiente institucional e de convivência dos CAPS como mediador desse projeto terapêutico.

Dessa forma, as intervenções do analista não estão definidas antecipadamente, mas buscam, posteriormente, o estabelecimento das escoras simbólicas de seu ato. Como se pode concluir do acima referido, a disponibilidade do analista no contexto psicossocial não é pensada como uma espera passiva, mas vista como uma atitude instigadora e provocadora de efeitos no sujeito que circula nesse ambiente, evento que transforma os dispositivos e os espaços em lugares de clínica.

Nesse sentido, o compromisso do analista diz respeito a sustentar a função do sintoma mais do que buscar o sentido e a significação do mesmo, testemunhando e interrogando sobre as escolhas que recaem para o sujeito nos diferentes dispositivos clínicos em que participa no CAPS. Com isso, a ética do bem dizer, 
é aquela relativa a fazer o sujeito dizer sobre o que sustenta o gozo em suas manifestações, implicando-o quanto ao destino do seu sintoma, no qual o que está em jogo não é a melhor escolha, mas qual é a escolha possível que produza satisfação e o inscreva no laço social.

\section{Referências}

Chemama, R. (Org.). Dicionário de psicanálise. Porto Alegre: Artes Médicas, 1995.

Figueiredo, A.C. Conferência no X Congresso do Laboratório de Psicopatologia Fundamental, Curitiba, 4 a 7 de setembro de 2010.

Figueiredo, A.C.; Machado, O.R. O diagnóstico em psicanálise: do fenômeno à estrutura. Ágora, Rio de Janeiro, v. 3, n. 2, p. 65-86, nov. 2000.

FReUd, S. (1895). Projeto para uma psicologia científica. In: Edição Standard Brasileira das Obras Psicológicas Completas de Sigmund Freud. Rio de Janeiro: Imago, 1996. V. I.

. (1900). A interpretação dos sonhos. In: Edição Standard Brasileira das Obras Psicológicas Completas de Sigmund Freud. Rio de Janeiro: Imago, 1996. V. IV e V. . (1907). Sobre a psicoterapia. In: Edição Standard Brasileira das Obras Psicológicas Completas de Sigmund Freud. Rio de Janeiro: Imago, 1996. V. VII. . (1912). Recomendações aos médicos que exercem a psicanálise. In: Edição Standard Brasileira das Obras Psicológicas Completas de Sigmund Freud. Rio de Janeiro: Imago, 1996. V. XII.

. (1913). Sobre o início do tratamento. In: Edição Standard Brasileira das Obras Psicológicas Completas de Sigmund Freud. Rio de Janeiro: Imago, 1996. V. XII.

. (1919). Linhas de progresso na terapia psicanalítica. In: Edição Standard Brasileira das Obras Psicológicas Completas de Sigmund Freud. Rio de Janeiro: Imago, 1996. V. XVII.

. (1925). Notas adicionais sobre a interpretação dos sonhos como um todo. In: Edição Standard Brasileira das Obras Psicológicas Completas de Sigmund Freud. Rio de Janeiro: Imago, 1996. V. XIX.

. (1930). O mal-estar na civilização. In: Edição Standard Brasileira das Obras Psicológicas Completas de Sigmund Freud. Rio de Janeiro: Imago, 1996. V. XXI.

KeHL, M.R. Sobre ética e psicanálise. São Paulo: Companhia das Letras, 2002.

LACAN, J. Função e campo da fala e da linguagem em psicanálise. In: Escritos. Rio de Janeiro: Jorge Zahar, 1998. 


\section{SAÚDE MENTAL}

(1959). O seminário. Livro 7. A ética da psicanálise. Rio de Janeiro: Jorge Zahar, 1991.

Monteiro, C.; QueIroz, E. A clínica psicanalítica das psicoses em instituições de saúde mental. Psicologia clínica. Rio de Janeiro, v. 18, n. 1, p. 109-121, 2006.

Quinet, A. A estranheza da psicanálise: a escola de Lacan e seus analistas. Rio de Janeiro: Jorge Zahar, 2009.

Rinaldi, D.; Alberti, S. Psicanálise, Saúde Mental e Universidade. Estudos e Pesquisas em Psicologia, Rio de Janeiro, ano 9, n. 2, p. 533-545, 2009.

\section{Resumos}

(The ethical dimension $\mathrm{f}$ analyst's interventions facing institutional demands of CAPS)

Considering the complexities involved in setting up clinical work in the psychosocial field, analyst must question their own contributions toward improvements in this area. This issue is presented here as a considerable challenge, due to the limitations of psychoanalytic practice and, especially, the differences between conventional clinical practice and that carried out in institutional and political settings. From this perspective, we call attention to the notion of ethics as a differentiating and guiding concept for psychoanalytic practice in its contribution toward the treatment provided at CAPS.

Key words: Psychoanalytic clinic, psychosocial, ethics, health care

(La dimension de l'éthique dans les interventions de l'analyste face à demandes institutionnelles des Centres de soins psychosociaux [CAPS])

Face à la complexité qui implique la construction de la clinique dans le domaine psychosocial, il appartient à l'analyste de s'interroger sur sa contribution à la qualification de cette proposition. Cela se présente comme un défi singulier, dû aux questions concernant les limites de la pratique psychanalytique, en considérant la différence comme un modèle clinique conventionnel et la présence des croisements institutionnels et politiques. Dans cette perspective, nous présentons la notion de l'éthique comme un concept qui différencie et qui oriente la clinique psychanalytique dans sa contribution aux prises en charge réalisées par les CAPS.

Mots clés: Clinique psychanalytique, clinique psychosocial, éthique, santé mentale

(La dimensión de la ética en las intervenciones del analista frente a las demandas institucionales de los CAPS - Centro de Atendimiento Psicosocial)

Frente a la complejidad que envuelve la construcción de la clínica en el campo psicosocial, le conviene al psicoanalista interrogarse sobre su contribución en la cualificación de esa propuesta. La cuestión se presenta como un desafío particu- 
lar ou peculiar, pues resulta (resultante) de los cuestionamientos acerca de los límites de la práctica psicoanalítica, teniendo en consideración la diferencia con el padrón clínico convencional y la presencia de los entrecruzamientos institucionales y políticos. Dentro de esta perspectiva, indicamos la noción de ética como un concepto que permite diferenciar y orientar la clínica psicoanalítica en su contribución a los tratamientos ofrecidos en los CAPS

Palabras claves: Clínica psicoanalítica, clínica psicosocial, ética, salud mental

(Dimension der Ethik bei Eingriffen des Analytikers im Rahmen der institutionellen Nachfrage der CAPS [Centro de Atenção Psicossocial-Psychosozialen Beratungszentren])

Angesichts der Komplexität der klinischen Strukturierung im psychosozialen Bereich, ist es Funktion des Analytikers sich zu fragen, welcher sein Beitrag zur Qualifikation dieses Ansatzes ist. Diese Frage stellt sich als besondere Herausforderung, infolge der Fragen zu den Grenzen der psychoanalytischen Praxis, unter Beachtung der Unterscheidung zum üblichen klinischen Standard und den institutionellen und politischen Überlappungen (se atravessamento for no sentido de sobreposição//coincidências) /ou/ Interferenzen (se for no sentido de ,interferências). Unter diesem Gesichtspunkt weisen wir auf die Auffassung von Ethik als Unterscheidungs- und Richtungsweisender Begriff der psychoanalytischen Klinik im Rahmen ihres Beitrages zu den von CAPS angebotenen Behandlungen hin.

Schlüsselwörter: Psychoanalytische Klinik, psychosozial, Ethik, geistige Gesundheit

Citação/Citation: DASSOLER, V.A.; PALMA, C.M.de S. A dimensão da ética nas intervenções do analista frente às demandas institucionais dos CAPS. Revista Latinoamericana de Psicopatologia Fundamental, São Paulo, v. 15, n. 1, p. 94-107, março 2012.

Editor do artigo/Editor: Profa. Dra. Ana Cristina Costa de Figueiredo e Profa. Dra. Andréa Máris Campos Guerra.

Recebido/Received: 9.5.2011 / 5.9.2011 Aceito/Accepted: 25.8.2011 / 8.25.2011

Copyright: () 2009 Associação Universitária de Pesquisa em Psicopatologia Fundamental/ University Association for Research in Fundamental Psychopathology. Este é um artigo de livre acesso, que permite uso irrestrito, distribuição e reprodução em qualquer meio, desde que $\mathrm{o}$ autor e a fonte sejam citados/This is an open-access article, which permits unrestricted use, distribution, and reproduction in any medium, provided the original author and source are credited.

Rev. Latinoam. Psicopat. Fund., São Paulo, v. 15, n. 1, p. 94-107, março 2012 
Financiamento/Funding: Os autores declaram não ter sido financiados ou apoiados/The authors have no support or funding to report.

Conflito de interesses/Conflict of interest: Os autores declaram que não há conflito de interesses/The authors declare that has no conflict of interest.

\section{Volnei ANTonio Dassoler}

Psicanalista; membro da Associação Psicanalítica de Porto Alegre - APPOA (Porto Alegre, RS, Br.); Mestre em Psicologia Universidade Federal de Santa Maria (Santa Maria, RS, Br.); integrante do CAPS ad Caminhos do Sol (Santa Maria, RS, Br.).

Rua Tiradentes, 76/401

97050-730 Santa Maria, RS, Br.

Fone: (55) 9964-3070

e-mail: dassoler@terra.com.br

\section{Claudia Maria de Sousa Palma}

Psicanalista; Profa. Adjunta do Depto de Psicologia e Psicanálise da Universidade Estadual de Londrina (Londrina, PR, Br); Dra. em Saúde Mental pela Faculdade de Medicina da UIniversidade de São Paulo - USP / Campus Ribeirão Preto (Ribeirão Preto, SP, Br); Pós-Doutora pelo Laboratório de Psicopatologia Fundamental do Depto de Psicologia Médica e Psiquiatria da Universidade Estadual de Campinas - Unicamp (Campinas, SP, Br).

Av. Madre Leonia Milito, 2000/1301 - Bela Suiça

86050-270 Londrina, PR, Br.

e-mail: cacaupalma@gmail.com 